\title{
PENGEMBANGAN PRODUK BARU UNTUK MENDUKUNG STRATEGI BISNIS PERUSAHAAN MINERAL INDUSTRIAL (STUDI KASUS: PT. XYZ)
}

\author{
NEW PRODUCT DEVELOPMENT TO SUPPORT BUSINESS STRATEGY IN \\ INDUSTRIAL MINERAL COMPANY (CASE STUDY: PT. XYZ) \\ Chandra Adiputra Tarigan ${ }^{*} 1$, Machfud ${ }^{* *}$, dan Arief Safari ${ }^{* * *}$ \\ *) Sekolah Bisnis, IPB University \\ Jl. Raya Pajajaran, Bogor 16151 \\ ${ }^{* *}$ Departemen Teknologi Industri Pertanian, Fakultas Teknologi Pertanian, IPB University \\ Kampus IPB Darmaga PO BOX 220, Bogor 16002 \\ ${ }^{* * *)}$ Institut Teknologi dan Bisnis Ahmad Dahlan \\ Jl. Ciputat Raya No. 77 Cireundeu, Ciputat 15419
}

\begin{abstract}
As the pioneer in the industrial mineral industry in Indonesia, PT. XYZ had experienced rapid growth and enjoy the market leader position; however, the trend shows that the sales volume recently decreases as an impact of tight competition and regulation control from the government. It is decided to formulate strategies to able the company growth and to maintain its strong position in the market. This study evaluated and analyzed the company's business environment internally and externally to find the alternative strategies suit best for PT. XYZ. Then, The strategies cascaded down into the functional strategy to prioritize the new product development (NPD) portfolio. The analysis used Internal Factor Evaluations (IFE) Matrix, External Factor Evaluation (EFE) Matrix, Five Forces Porter Matrix, Internal-External (IE) Matrix, Boston Consulting Group (BCG) Matrix, Quantitative Strategic Planning (QSPM) Matrix and Analytic Hierarchy Process (AHP). The research was conducted with a purposive sampling technique by selecting internal and external experts. The results show that market development, market penetration, retrenchment, and product development were the strategy that must be implemented for the particular market segment, while Product $A$ was the most prioritize NPD portfolio to be developed by PT. XYZ.
\end{abstract}

Keywords: industrial mineral, business strategy, functional strategy, NPD, AHP

\begin{abstract}
Abstrak: Sebagai perusahaan perintis dalam industri manufaktur mineral industrial di Indonesia, PT. XYZ telah mengalami pertumbuhan cepat dan menikmati posisinya sebagai pemimpin pasar; namun tren akhir-akhir ini menunjukkan penurunan penjualan akibat persaingan industri dan peraturan perundang-undangan yang semakin ketat. Oleh karena itu dilakukan penelitian ini dengan tujuan untuk merumuskan strategi yang tepat agar perusahaan tetap bertumbuh dan mempertahankan posisinya di pasar. Metode yang dipakai dalam penelitian adalah pendekatan kualitatif dengan cara mengevaluasi lingkungan internal dan eksternal perusahaan untuk mencari alternatif strategi bisnis yang sesuai bagi PT. XYZ. Strategi bisnis tersebut kemudian diturunkan ke dalam strategi fungsional untuk menentukan prioritas pengembangan produk baru. Metode analisis yang digunakan adalah IFE Matrix, EFE Matrix, Five Forces Porter, IE Matrix, BCG Matrix, QSPM Matrix dan Analytic Hierarchy Process (AHP). Penelitian dilakukan menggunakan teknik purposive sampling dengan memilih panel ahli yang berkompeten dari internal dan eksternal. Hasil penelitian menunjukkan bahwa strategi pengembangan pasar, penetrasi pasar, pengetatan biaya dan pengembangan produk adalah strategi yang paling sesuai dilakukan untuk segmen pelanggan tertentu dan produk A sebagai portfolio produk baru yang prioritas untuk dikembangkan.
\end{abstract}

Kata kunci: mineral industrial, strategi bisnis, strategi fungsional, produk baru, AHP

\footnotetext{
${ }^{1}$ Corresponding author:

Email: chan.tarigan.ct@gmail.com
} 


\section{PENDAHULUAN}

Manajemen portofolio produk, baik portofolio produk yang telah eksis (existing product) maupun portofolio produk baru new product development (NPD), merupakan suatu bidang manajemen yang telah bertumbuh menjadi bagian penting (Cooper et al. 1997a) dan tidak terpisahkan bagi perusahaan dalam menghadapi persaingan global (Killen et al. 2008). Sebagai suatu alat manajemen dan bagian dari sebuah strategi bisnis, optimalisasi portofolio produk merupakan hal yang harus direncanakan dan dilakukan oleh perusahaan untuk: (1) menghasilkan pertumbuhan (Cooper et al. 1997a); (2) keseimbangan bisnis (Gorbos, 2016), (Killen et al. 2008); (3) memaksimalkan kepuasan pelanggan dan proses bisnis internal (Lapide 2016) dan (4) agar tercipta keterhubungan/linking dengan strategi utama bisnis perusahaan (Cooper et al. 1997a).

Berbicara khusus mengenai portofolio produk baru/NPD, walaupun secara bisnis memiliki risiko ketidakpastian, memerlukan fleksibilitas operasional yang tinggi, kompleks dan sulit untuk diantisipasi (Clark dan Fujimoto 1991, Slack et al. 2007). Namun, di lain pihak NPD merupakan sumber keuntungan kompetitif perusahaan di masa depan (Clark and Fujimoto, 1991; McRea dan Elizabeth, 2004; Lofsten, 2014 ). Kemampuan perusahaan dalam menghasilkan inovasi portfolio produk baru akan semakin memegang peranan penting dalam penciptaan pertumbuhan inorganic perusahaan dibandingkan hanya sekedar memperbaiki/organic growth kinerja bisnis (Relich dan Bzdyra, 2014) karena saat ini rata-rata industri memiliki siklus hidup produk/product life cycle yang semakin pendek (Cooper et al. 1997b dan Cooper et al. 1998).

Artikel ini berusaha untuk menganalisis pengembangan portofolio produk baru yang mendukung strategi bisnis pada lingkup PT. XYZ, sebuah perusahaan mineral industrial di Indonesia. Alasan-alasan yang melatarbelakangi pemilihan topik ini dapat dilihat dari dua sisi. Pertama, dilihat dari sisi perusahaan, di mana PT. XYZ adalah unit bisnis bagian dari korporat mineral industrial yang cukup besar yang sedang berada dalam tahap transformasi bisnis. Salah satu arahan (direction) korporasi yang telah digariskan dalam transformasi bisnis jangka panjang adalah agar setiap unit bisnis mampu bertumbuh dan berkembang tidak hanya terbatas pada pasar mineral industrial yang telah ada saat ini tetapi harus terus mencari peluang jauh di luar/beyond mineral industrial yang telah eksis. Arahan ini menuntut setiap unit bisnis untuk aktif dalam NPD sehingga diharapkan $10 \%$ revenue setiap tahunnya berasal dari produk-produk baru yang diperkenalkan ke pasar dalam kurun waktu 5 tahun terakhir (Buku visi korporasi, 2020). Kedua, dari sisi industri, di mana (1) Indonesia memiliki tingkat keberagaman, keterdapatan, jumlah deposit mineral industrial yang sangat menjanjikan, menjadikannya sebagai salah satu industri dengan rentang portofolio produk yang dapat dikembangkan dengan sangat luas; (2) tren mineral industrial di Indonesia, sesuai dengan Permendag No. 119 tahun 2015 tentang Ketentuan Ekspor Produk Pertambangan Hasil Pengolahan dan Pemurnian, yang pada hakikatnya memiliki roh untuk lebih mensejahterakan negara dengan cara melakukan proses penambahan nilai (value added process) pengolahan dan pemurnian mineral yang dilaksanakan di negara Indonesia. Peraturan ini membuat perusahaan mineral harus berfikir untuk terus berinovasi dalam hal teknologi, proses produksi dan produk; (3) Pentingnya pengembangan produk-produk baru bagi pertumbuhan bisnis perusahaan mineral industrial yang telah disampaikan oleh beberapa peneliti (Wilson dan Amavilah, 2007;Katsioleris, 2011; Lismore, 2014; Merriman, 2016).

Sejak berdiri dan mulai beroperasi di tahun 1990-an, PT. XYZ dapat digolongkan sebagai perusahaan perintis/ first mover dalam bisnis mineral industrial di Indonesia dan menikmati masa jayanya sebagai pemimpin pasar/ market leader seiring dengan pertumbahan organik industri keramik ubin dan keramik sanitaryware/ tableware sebagai pelanggan utamanya. Namun, akhir-akhir ini PT. XYZ mengalami banyak tantangan dari luar dan dalam perusahaan yang mengakibatkan penurunan indikator akhir/bottom line kinerja penjualan tahun 2016 sebesar 16,1\% terhadap volume dan 4,8\% terhadap revenue perusahaan jika dibandingkan kinerja tahun 2014. Penurunan ini terjadi di hampir semua portfolio produk PT. XYZ dan hampir di semua segmen industri pelanggan seperti ditunjukkan Gambar 1.

Di sisi lain, kinerja pengembangkan portofolio NPD PT. XYZ yang memiliki nilai tambah lebih dan berbeda dibandingkan produk dari pesaing dinilai masih perlu ditingkatkan agar sejalan dengan arahan stratejik dari korporat. Data internal PT. XYZ mengungkapkan dua fakta mengenai kinerja NPD PT. XYZ. Pertama dari sisi jumlah, pada tahun 2015 dan 2016 terjadi penurunan 
jumlah portofolio produk baru yang berhasil dipasarkan. Kedua dari sisi revenue penjualan, di mana hanya dua dari total tujuh NPD yang relatif berhasil bertumbuh dengan cukup baik. Sehubungan dengan permasalahan bisnis yang dihadapi PT. XYZ maka perlu dirumuskan strategi bisnis yang sesuai dengan kondisi eksternalinternal perusahaan saat ini agar perusahaan tetap bertumbuh dan mempertahankan posisinya di pasar dan ditentukan strategi fungsional berupa prioritasi pilihan NPD yang harus dikembangkan agar sesuai dengan visi dan arahan stratejik (strategic direction) korporat.

\section{METODE PENELITIAN}

Penelitian dilakukan di PT. XYZ yang berlokasi di daerah Jawa Barat. Pemilihan lokasi penelitian dilakukan dengan sengaja dengan pertimbangan bahwa manajemen perusahaan tersebut bersedia untuk dijadikan obyek penelitian. Pelaksanaan penelitian dilakukan selama dua bulan dimulai dari bulan Agustus sampai September 2018.

Jenis data yang dipakai meliputi data primer dan data sekunder. Data primer dihimpun melalui wawancara mendalam (in-depth interview), pengisian kuisioner terhadap pihak internal manajemen PT. XYZ dan pakar eksternal dari perusahaan. Focus Group Discussion (FGD) dengan pakar dilaksanakan untuk mendapatkan sebuah kesepakatan terhadap suatu masalah yang lebih kompleks. Responden pakar dipilih secara sengaja dengan kriteria para praktisi mineral industrial dan para profesional yang memiliki hubungan kerja dengan PT. XYZ sehingga diperoleh informasi yang lebih akurat. Data sekunder berupa data internal perusahaan seperti data penjualan dan data produksi. Data lain diperoleh dari jurnal, buku, tesis dan sumber lain yang berhubungan.

Pengolahan dan analisis data dilakukan dalam beberapa tahapan, yaitu identifikasi dan evaluasi lingkungan eksternal dekat, eksternal jauh dan internal perusahaan untuk mendapatkan faktor penting internal-eksternal perusahaan dengan menggunakan matrix IFE dan EFE (tahap input), memadukan data faktor internal dan eksternal untuk mendapatkan alternatif strategi yang tersedia menggunakan matrix BCG dan matrix IE (tahap matching) dan selanjutnya dilakukan pemilihan strategi yang paling sesuai menggunakan Matrix QSPM (tahap decision). Prioritas NPD sebagai strategi fungsional dianalisis dan dipilih dengan menggunakan metode AHP. Kerangka penelitian dijelaskan Gambar 2.

\section{HASIL}

\section{Formulasi Strategi Bisnis}

Tahap Input (input stage)

Tahapan ini bertujuan mengidentifikasi dan mengevaluasi lingkungan eksternal dekat, eksternal jauh dan dan internal perusahaan, agar dihasilkan masukan alternatif startegi yang tepat. Identifikasi dan evaluasi lingkungan eksternal dekat menggunakan Five Forces Porter Matrix mendapatkan data rating persaingan di industri mineral industrial seperti ditunjukkan Tabel 1.

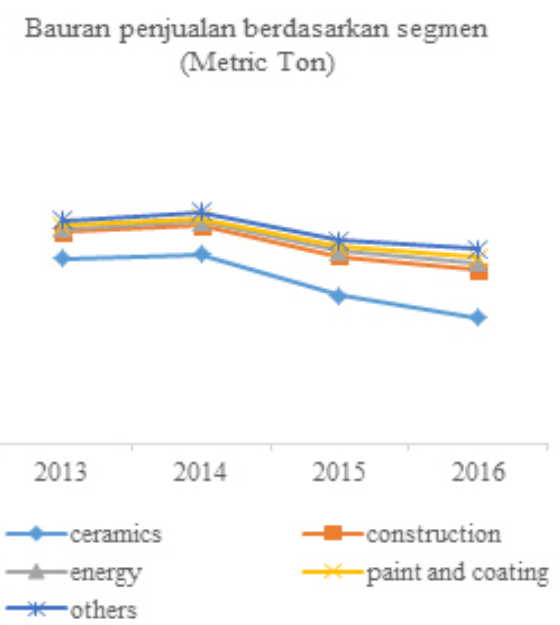

Gambar 1. Bauran penjualan -Ton PT XYZ 


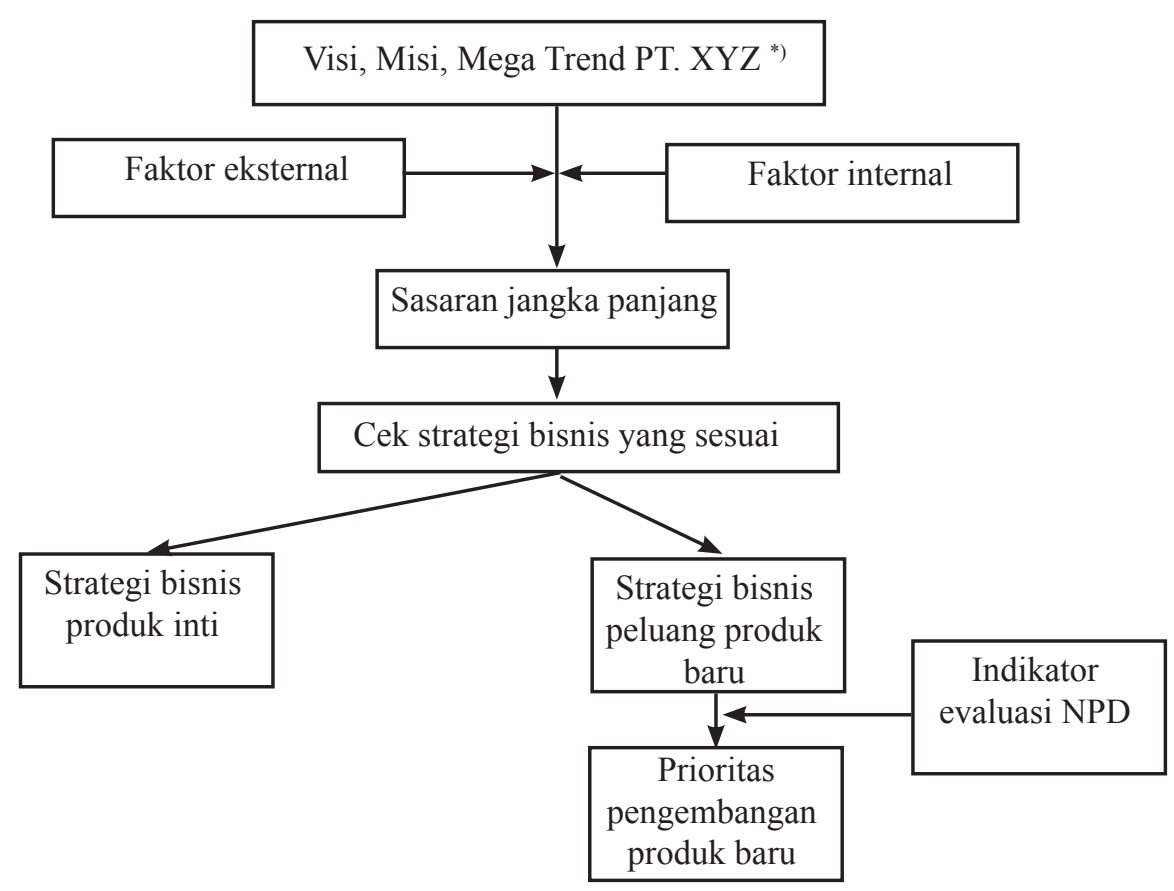

Gambar 2. Kerangka pemikiran penelitian $\left({ }^{*}\right)$ Visi, misi dan mega trend telah digariskan/given dari korporat)

Tabel 1. Five Forces Porter Matrix lingkungan industry PT. XYZ

\begin{tabular}{|c|c|c|c|c|c|}
\hline \multirow{4}{*}{ Faktor eksternal dekat } & \multicolumn{5}{|c|}{ Rating } \\
\hline & \multicolumn{4}{|c|}{ Menguntungkan } & \multirow{2}{*}{$\stackrel{\text { Mengancam }}{\longrightarrow}$} \\
\hline & & & & & \\
\hline & SU & $\mathrm{U}$ & $\mathrm{N}$ & A & SA \\
\hline Rivalitas antar perusahaan. & & & $\mathrm{v}$ & $\mathrm{X}$ & \\
\hline Kekuatan tawar pelanggan & & & & $\mathrm{X}$ & \\
\hline Kekuatan tawar pemasok & $\mathrm{v}$ & $\mathrm{X}$ & & & \\
\hline Ancaman produk substitusi & $\mathrm{X}$ & & & & \\
\hline Ancaman pendatang baru & & & & $\mathrm{X}$ & \\
\hline
\end{tabular}

Pergeseran faktor rivalitas antar perusahaan akan menjadi lebih mengancam industri di masa depan karena beberapa alasan, yaitu 1) sifat produk yang diminta pelanggan sangat standar, 2) gap kompetensi, teknologi dan akses bahan baku yang semakin tipis antara perusahaan yang bersaing, dan 3) potensi masuknya dua pesaing baru ke industri ini. Di sisi kekuatan tawar pemasok, diprediksi akan mengurangi keuntungan industri akibat isu ekploitasi berlebih yang dilakukan pemasok dan mayoritas pemasok tidak memiliki pengolahan lanjutan di tambang sehingga keberlanjutan pasokan bahan baku berkualitas akan tergangu. Di samping itu, praktik yang dijalankan oleh pemasok-pemasok saat ini tentu sangat mengancam kelestarian lingkungan hidup yang telah menjadi isu hangat nasional dan global.
Evaluasi faktor eksternal dekat dan eksternal jauh dilakukan menggunakan EFE Matrix dengan hasil seperti ditunjukkan Tabel 2. Untuk faktor peluang, nilai bobot tertinggi berdasarkan penilaian panel internal adalah faktor gulung tikarnya satu perusahaan pesaing lokal dengan bobot sebesar 0,15 . Hal ini menurut analisis penulis sejalan dengan evaluasi matrix faktor eksternal dekat terutama faktor rivalitas antar perusahaan yang dinilai cenderung mengancam pelaku industri ini di masa depan. Sedikit saja permasalahan bisnis yang dihadapi oleh pesaing akan menjadi peluang signifikan yang sangat menguntungkan perusahaan lainnya. Faktor peluang dengan nilai bobot tertinggi berikutnya adalah proyeksi pertumbuhan industri keramik Indonesia dengan bobot 0,1 dan larangan import bahan baku keramik frit dari China oleh pemerintah Indonesia 
dengan bobot sama 0,1 . Kedua faktor peluang ini berasal darisegmen pasar keramik ubin yang merupakan segmen pasar utama dengan persentasi penjualan terbesar bagi industri mineral industrial di Indonesia. Peningkatan produksi pada pelanggan segmen pasar utama tentu akan mempengaruhi peningkatan penjualan mineral industrial ke pelanggan tersebut dan akan menjadi peluang yang sangat menguntungkan perusahaan.

Respon yang telah diberikan oleh PT XYZ untuk memanfaatkan peluang dan luar dapat dilihat pada kolom nilai dalam Matrix EFE. Beberapa langkah strategis telah dilakukan dengan sangat baik oleh PT. XYZ untuk memanfaatkan faktor-faktor peluang eksternal khususnya no. 1, 4, 5 dan 6 yakni Melakukan strategi harga bersaing khusus pada pelanggan keramik yang mendapatkan proyek sejuta rumah pemerintah. Langkah strategis ini dinilai sangat memuaskan oleh panel ahli dalam upaya PT. XYZ memanfaatkan peluang proyeksi pertumbuhan industri keramik tahun 2019-2023; Mendapatkan ijin ekspor terbatas material clay. Langkah ini sangat strategis bagi pertumbuhan bisnis segmen keramik ubin pasar ekspor ketika keran eksport terbatas mineral industrial sudah dibuka oleh pemerintah Indonesia; Mendapatkan kembali volume penjualan yang selama ini direbut oleh pesaing yang telah gulung tikar melalui pendekatan kepercayaan bersama (mutual trust); Memberikan service pengiriman barang yang fleksibel bagi pelanggan yang mendapatkan limpahan order akibat dari larangan impor frit dari China. Dengan fleksibilitas ini membuat beberapa masalah produksi di pelanggan teratasi dan meningkatkan hubungan baik pelanggan-PT. XYZ.

Untuk faktor ancaman, nilai bobot tertinggi berdasarkan penilaian panel internal adalah potensi persaingan akibat masuknya pendatang baru (PT. Y, PT. A dan PT. B) dan potensi backward integration dari customer utama PT. AB dengan bobot berurutan sebesar 0.1, 0.12 dan 0.12 . Menurut analisa penulis, tingginya nilai pembobotan yang diberikan oleh panel internal sejalan dengan penilaian pada matrix evaluasi faktor eksternal dekat terutama faktor potensi masuknya pesaing baru dimana panel internal menilai akan mengancam keberlangsungan bisnis perusahaan.

Tabel 2, EFE Matrix PT, XYZ

\begin{tabular}{lccc}
\hline Peluang & Bobot & Nilai & Skor \\
\hline Proyeksi pertumbuhan industri keramik & 0,1 & 4 & 0,4 \\
Proyeksi pertumbuhan Industri bata ringan & 0,05 & 1 & 0,05 \\
Peningkatan kapasitas industri CPO & 0,05 & 1 & 0,05 \\
Pembukaan eksport terbatas mineral & 0,08 & 4 & 0,32 \\
Satu perusahaan pesaing lokal bangkrut & 0,15 & 4 & 0,6 \\
Larangan import bahan baku keramik oleh pemerintah Indonesia & 0,10 & 4 & 0,4 \\
\hline Ancaman & & \\
\hline Korporasi global Y sudah masuk ke pasar mineral tanah liat di Indonesia & 0,1 & 1 & 0,10 \\
Dua pesaing lokal sedang membangun fasilitas produksi tepung mineral & 0,12 & 1 & 0,12 \\
Ada sinergi dari trader-trader mineral industrial Indonesia & 0,04 & 4 & 0,16 \\
Perusahaan mineral logam di Indonesia merambah ke industri mineral industrial & 0,04 & 4 & 0,16 \\
Bubbling harga rumah premium & 0,05 & 3 & 0,15 \\
Backward integration pelanggan penting & 0,12 & 1 \\
\hline Total & 1,0 & & 2,63 \\
\hline
\end{tabular}


Respon yang telah diberikan oleh PT XYZ untuk meminimalkan ancaman dan luar dapat dilihat pada kolom nilai dalam Matrix EFE. Beberapa langkah strategis telah dilakukan dengan sangat baik oleh PT. XYZ untuk meminimalkan faktor-faktor ancaman eksternal khususnya no. 3, 4 dan 5 yakni Mendapatkan kontrak pembelian jangka panjang dari salah satu pemasok pasir berkualitas. Langkah ini sangat strategis untuk meminimalkan dampak yang ditimbulkan oleh sinergi strategis trader bahan baku yang berusaha untuk mendapatkan untung berlebih dari permainan harga pasir; Terus menjalin hubungan erat dengan pelanggan yang selama ini melakukan bisnis dengan PT. XYZ. Hubungan erat tersebut dilakukan dengan pengembangan produk baru bersama (joint product development) dan kunjungan/penilaian pabrik oleh pelanggan. Langkah ini sangat efektif untuk membentuk ikatan yang kuat dengan pelanggan dan mencegah masuknya pendatang baru yang tidak memiliki kempetensi inti (core competency) di bidang mineral industrial; Telah melakukan strategi product-mix antara pelanggan kelas premium, kelas menengah dan kelas bawah. Product mix yang dilakukan tersebut terbukti efektif mampu meminimalkan efek dari kondisi bubbling rumah premium saat ini.
Hasil analisis EFE matrix, dengan skor total 2,63, PT. XYZ dinilai sudah cukup efektif dalam memanfaatkan peluang dan mengatasi ancaman penting dari luar perusahaan. Untuk membawa PT. XYZ ke level yang lebih tinggi, manajemen harus lebih fokus dalam strategi untuk merespons faktor-faktor ancaman terutama potensi masuknya pesaing baru (baik lokal dan global) serta backward integration yang dilakukan oleh salah satu pelanggan penting perusahaan.

Evaluasi faktor internal dilakukan menggunakan IFE Matrix dengan hasil seperti ditunjukkan Tabel 3. Untuk faktor kekuatan, nilai bobot tertinggi adalah faktor kualitas produk yang dipersepsikan sangat baik dan konsisten oleh pelanggan utama terutama segmen keramik ubin dengan bobot 0.08 . Hal ini menurut analisa penulis sejalan dengan informasi bahwa segmen pasar keramik ubin sebagai segmen pasar utama PT. $\mathrm{XYZ}$ harus terus dipelihara agar perusahaan dapat mempertahankan posisinya sebagai pemimpin pasar di segmen tersebut. Kekuatan kedua terbesar adalah lokasi pabrik yang relatif lebih dekat ke mayoritas pelanggan segmen keramik ubin dengan bobot 0.07 yang sudah barang tentu menjadi sebuah keunggulan komparatif bagi PT. XYZ dalam menyediakan produk dengan biaya logistik dan fleksibilitas operasional pengiriman yang lebih baik.

Tabel 3. IFE Matrix PT. XYZ

\begin{tabular}{|c|c|c|c|}
\hline Kekuatan & Bobot & Nilai & Skor \\
\hline Dukungan pusat teknikal dan inovasi & 0,03 & 3 & 0,09 \\
\hline Portofolio mineral industri beragam & 0,04 & 3 & 0,12 \\
\hline Hubungan yang baik dengan pelanggan & 0,03 & 3 & 0,09 \\
\hline Tingkat kepuasan pelanggan tinggi terhadap kualitas & 0,08 & 4 & 0,32 \\
\hline Branding produk yang sangat kuat & 0,03 & 3 & 0,09 \\
\hline Fleksibilitas produksi yang cukup tinggi & 0,05 & 4 & 0,2 \\
\hline Dukungan keuangan yang cukup kuat. & 0,02 & 3 & 0,06 \\
\hline Team marketing yang solid & 0,03 & 3 & 0,09 \\
\hline Lokasi pabrik dekat dengan pelanggan & 0,07 & 4 & 0,28 \\
\hline Nilai depresiasi mesin sudah kecil & 0,02 & 4 & 0,08 \\
\hline \multicolumn{4}{|l|}{ Kelemahan } \\
\hline Proses pengambilan keputusan strategis yang terpusat secara global. & 0,03 & 2 & 0,06 \\
\hline Komponen biaya administrasi tinggi & 0,1 & 1 & 0,1 \\
\hline Komponen biaya bahan baku tinggi. & 0,15 & 2 & 0,30 \\
\hline Tidak memiliki sumber tambang sendiri & 0,12 & 2 & 0,24 \\
\hline Kerusakan mesin cukup sering terjadi & 0,05 & 2 & 0,1 \\
\hline Tingkat kepuasan pelanggan rendah terhadap harga & 0,15 & 2 & 0,3 \\
\hline Total & 1,0 & & 2,52 \\
\hline
\end{tabular}


Respon yang telah diberikan oleh PT XYZ untuk memanfaatkan kekuatan perusahaan dapat dilihat pada kolom nilai dalam Matrix IFE. Beberapa langkah strategis telah dilakukan dengan sangat baik oleh PT. XYZ untuk memanfaatkan faktor-faktor kekuatan perusahaan khususnya no. 4, 6, 9 dan 10, yakni Mendapatkan kontrak pembelian jangka panjang dari salah satu pemasok pasir berkualitas. Langkah ini sangat strategis untuk mempertahankan persepsi pelanggan akan kehandalan kualitas produk dibandingkan dengan pesaing lokal. Untuk menjamin kehandalan kualitas produk, PT. XYZ juga telah berinvestasi pada peralatan pengujian kualitas mineral industrial yang kapabel agar semua produk sesuai dengan persyaratan pelanggan; Melakukan strategi produksi multi mineral termasuk beberapa trial produk baru di masing-masing lini produksi. Strategi produksi ini dinilai mampu memanfaatkan kekuatan fleksibilitas produksi agar dapat meraih beberapa peluang produk baru; Melakukan pengiriman menggunakan bulk truck yang jauh lebih ekonomis dibandingkan dengan kemasan tertentu (jumbo bag atau paper bag). Langkah ini membuat biaya pengiriman menjadi lebih rendah dibandingkan pesaing yang lain dan dapat memberikan rasa aman akan aspek keterkiriman barang (supplyability).

Untuk faktor kelemahan, nilai bobot tertinggi berdasarkan penilaian panel internal adalah komponen biaya administrasi termasuk keselamatan dan kesehatan kerja yang cenderung cukup tinggi; komponen biaya produksi untuk bahan baku cukup tinggi; tingkat kepuasan pelanggan akan harga produk yang berada di level "kurang" dan faktor bahwa PT. XYZ tidak memiliki sumber tambang mineral industrial sendiri dengan bobot nilai berurutan $0,1,0,15,0,15$ dan 0,12 . Tiga faktor kelemahan pertama berkaitan erat dengan tingkat biaya produksi, dimana dalam sebuah industri yang mayoritas produknya terstandarisasi dan banyak pelanggan yang sensitif terhadap harga maka perusahaan harus melakukan strategi low cost (David, 2011), sehingga jika biaya produksi dianggap tinggi maka hal tersebut akan menjadi faktor kelemahan dan harus diperbaiki agar perusahaan dapat terus bersaing di industri tersebut. Faktor keempat adalah faktor PT. XYZ yang tidak memiliki sumber tambang mineral industrial sendiri khusus di mineral pasir silika sebagai mineral dengan volume terbesar. Faktor ini diberi bobot yang tinggi sejalan dengan penilaian panel internal pada evaluasi faktor daya tawar pemasok dimana ke depannya akan semakin sedikit pemasok yang dapat mengirimkan pasir dengan kualitas yang baik dan harga bersaing. Di samping itu, komponen biaya bahan baku pasir silika merupakan komponen biaya yang cukup tinggi dalam biaya produksi PT. XYZ. Peningkatan harga pada bahan baku pasir silika akan semakin meningkatkan biaya produksi dengan signifikan. Dengan menguasai sebuah tambang pasir yang bagus, baik dalam bentuk pengelolaan atau kemitraaan yang strategis, akan dapat menurunkan biaya produksi sekaligus mendapatkan pasokan bahan baku yang berkualitas.

Hasil analisis IFE matrix, dengan skor total sebesar 2,52 PT. XYZ dinilai sudah cukup efektif dalam memanfaatkan kekuatan dan berbenah untuk mengatasi kelemahan penting perusahaan. Untuk membawa PT. $\mathrm{XYZ}$ ke level yang lebih tinggi, manajemen harus lebih fokus dalam strategi untuk merespons faktor-faktor kelemahan biaya produksi dan administrasi perusahaan yang tinggi.

Tahap pemaduan (matching stage)

Dari hasil EFE matrix yang mendapatkan nilai 2,63 dan IFE matrix dengan nilai 2,52, dapat ditentukan posisi PT. XYZ dalam IE Matrix berada dalam kuadran hold and maintain seperti ditunjukkan Gambar 3. Alternatif strategi bisnis yang sesuai adalah penetrasi pasar dan pengembangan produk (David, 2011). Alternatif strategi bisnis perusahaan yang dihasilkan IE Matrix dianalisis keselarasannya dengan alternatif strategi bisnis per segmen pelanggan menggunakan BCG Matrix yang disajikan pada Gambar 4.

Dari BCG matrix PT XYZ, direkomendasikan pilihan alternatif strategi bisnis sebagai berikut (David, 2011): Strategi pengembangan produk, pengetatan biaya, diversification, atau divestiture untuk segmen keramik ubin (KU) yang berada di kuadran III (cash cow). Strategi pengetatan biaya (S1) dipilih sebagai strategi yang paling sesuai karena terjadi beberapa inefisiensi pada proses produksi dan tingginya frekuensi kejadian kerusakan mesin, menyebabkan meningkatnya biaya produksi perusahaan. Walaupun kompetensi inti PT. XYZ berada di segmen ini namun akibat dari inefisiensi tersebut, perusahaan sulit untuk mencapai keuntungan lebih tinggi seperti yang diharapkan oleh korporat. Pilihan strategi pengetatan biaya ini sejalan dan mendukung strategi penetrasi pasar yang dihasilkan IE Matrix, di mana penetrasi pasar yang dilakukan membutuhkan ruang untuk strategi harga yang dapat lebih bersaing di pasar (Ansoff dan McDonell, 1990). 


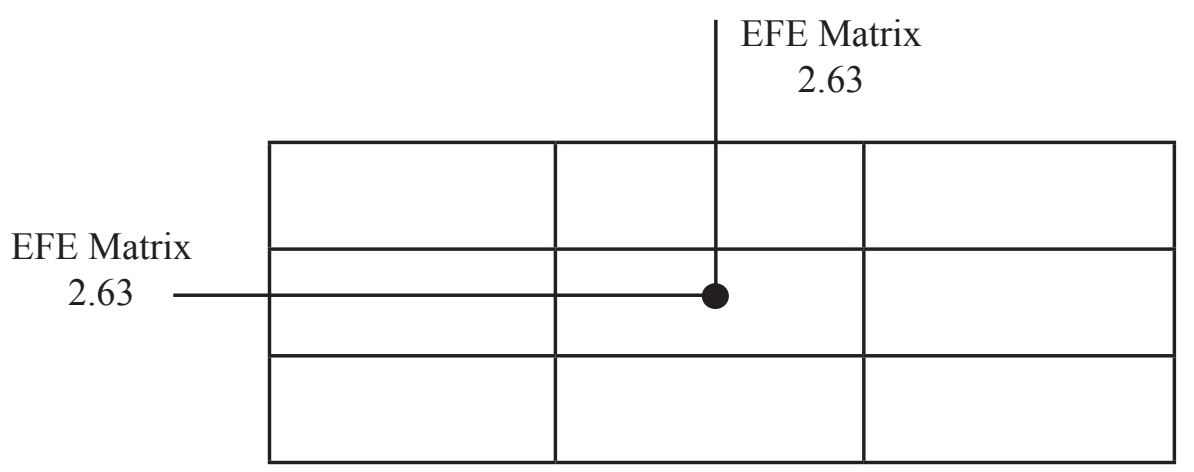

Gambar 3. IE Matrix PT. XYZ

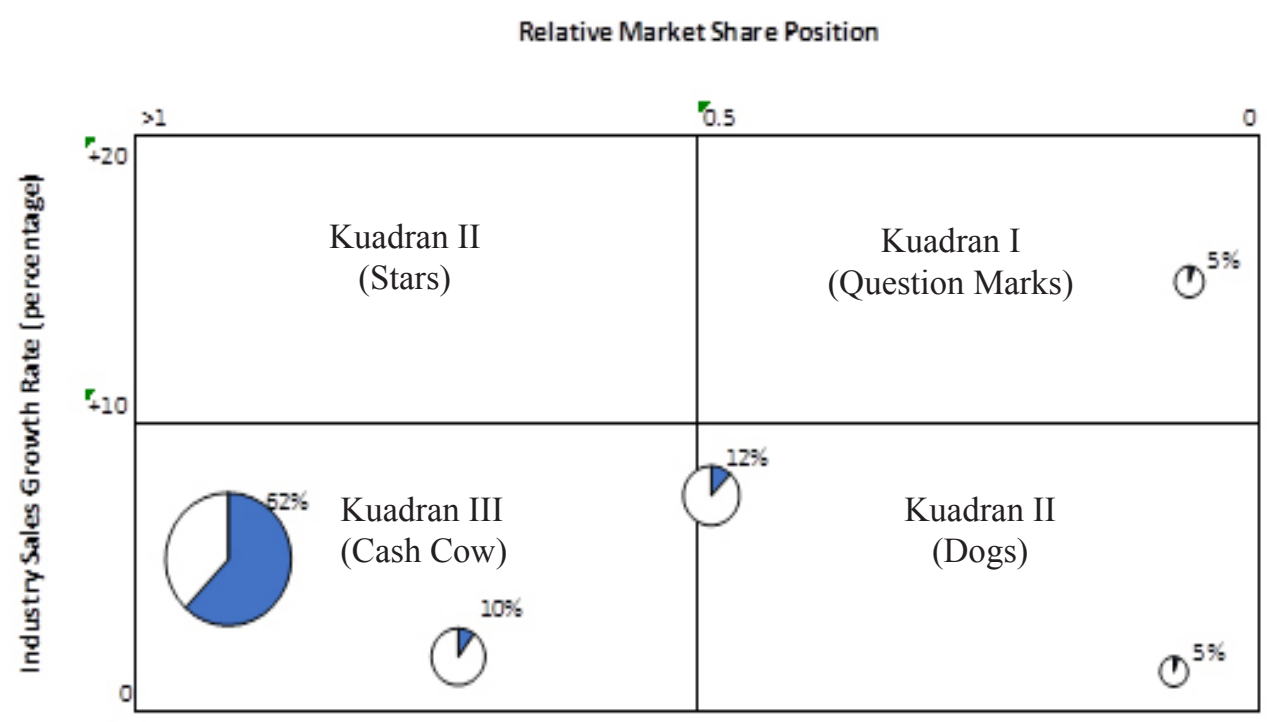

Gambar 4. Matrix BCG PT. XYZ

Strategi pengetatan biaya, divestiture atau liquidation untuk segmen konstruksi (KK) dan energi (EE) yang berada di kuadran IV ( $\operatorname{dog} s)$. Strategi pengetatan biaya (S2) dinilai paling sesuai dijalankan untuk memperbaiki inefisiensi yang ada sampai segmen pasar kembali bertumbuh dengan baik. Strategi divestiture dan liquidation juga dinilai sesuai untuk dilaksanakan namun kewenangan keputusan strategi ini berada di level korporat.

Strategi penetrasi pasar, pengembangan pasar dan pengembangan produk untuk segmen cat dan coating (CC) yang berada di kuadran I (question marks). Ketiga strategi ini (S3) sesuai untuk dipilih setelah mempertimbangkan kondisi industri pelanggan yang berkembang dengan baik, sangat terbuka mendapatkan pasokan mineral berkualitas dari pemasok lokal dan secara internal PT. XYZ belum intens melakukan aktivitas pemasaran ke calon pelanggan lokal.
Strategi pengembangan produk, pengetatan biaya, diversification, atau divestiture untuk segmen sanitaryware/ tableware (ST) yang berada di kuadran III (cash cows). Strategi pengembangan produk (S4) lebih dipilih dibandingkan alternatif yang lain walaupun industri pelanggan bertumbuh pada tingkat yang tidak terlalu tinggi namun terbuka dan mengharapkan produk-produk baru yang dapat meningkatkan kualitas produk mereka.

Alternatif strategi masing-masing segmen bisnis yang dihasilkan dari analisa BCG Matrix cukup sejalan dengan alternatif strategi bisnis perusahaan hasil analisa IE Matrix. Perbedaaan hanya terletak pada alternatif strategi pengembangan pasar (market development) segmen pasar cat dan coating (CC) karena pertumbuhan pasar segmen industri $\mathrm{CC}$ sangat tinggi jauh di atas rata-rata pertumbuhan pasar segmen industri lainnya. 
Tahap keputusan (decision stage)

Keputusan strategi bisnis yang akan dipilih adalah berdasarkan tingkat keatraktifan relatif suatu strategi dibandingkan dengan strategi yang lain. Metode penilaian kuantitatif untuk membandingkan pilihan- pilihan strategi yang tersedia menggunakan QSPM Matrix. (S1 - S4) yang dihasilkan analisa BCG Matrix. Setiap strategi dinilai keatraktifannya bagi PT. XYZ berdasarkan faktor-faktor kunci perusahaan yang dihasilkan dari tahap input. Hasil analisa QSPM Matrix PT. XYZ disajikan pada Table 4.

Tabel 4. QSPM Matrix PT. XYZ

\begin{tabular}{|c|c|c|c|c|c|c|c|c|c|}
\hline \multirow{3}{*}{ Faktor } & \multirow{3}{*}{ Bobot } & \multicolumn{8}{|c|}{ Business Strategy Alternatives } \\
\hline & & \multicolumn{2}{|c|}{$\mathrm{S} 1$} & \multicolumn{2}{|c|}{$\mathrm{S} 2$} & \multicolumn{2}{|c|}{ S3 } & \multicolumn{2}{|c|}{ S4 } \\
\hline & & AS & TAS & AS & TAS & AS & TAS & AS & TAS \\
\hline \multicolumn{10}{|l|}{ Peluang } \\
\hline Proyeksi pertumbuhan industri keramik & 0,1 & 4 & 0,4 & 1 & 0,1 & 2 & 0,2 & 3 & 0,3 \\
\hline Pembukaan eksport terbatas mineral & 0,08 & 4 & 0,32 & 1 & 0,08 & 1 & 0,08 & 3 & 0,24 \\
\hline Satu perusahaan pesaing lokal bangkrut & 0,15 & 4 & 0,6 & 1 & 0,15 & 2 & 0,3 & 3 & 0,45 \\
\hline $\begin{array}{l}\text { Larangan import bahan baku keramik oleh pemerintah } \\
\text { Indonesia }\end{array}$ & 0,10 & 4 & 0,4 & 1 & 0,1 & 2 & 0,2 & 3 & 0,3 \\
\hline \multicolumn{10}{|l|}{ Ancaman } \\
\hline $\begin{array}{l}\text { Korporasi global Y sudah masuk ke pasar mineral tanah } \\
\text { liat di Indonesia }\end{array}$ & 0,1 & 3 & 0,3 & 1 & 0,1 & 2 & 0,2 & 4 & 0,4 \\
\hline $\begin{array}{l}\text { Dua pesaing lokal sedang membangun fasilitas produksi } \\
\text { tepung mineral }\end{array}$ & 0,12 & 1 & 0,12 & 2 & 0,24 & 3 & 0,36 & 4 & 0,48 \\
\hline Ada sinergi dari trader-trader mineral industrial Indonesia & 0,04 & 2 & 0,08 & 1 & 0,04 & 4 & 0,16 & 3 & 0,12 \\
\hline $\begin{array}{l}\text { Perusahaan mineral logam di Indonesia merambah ke } \\
\text { industri mineral industrial }\end{array}$ & 0,04 & 2 & 0,08 & 1 & 0,04 & 3 & 0,12 & 4 & 0,16 \\
\hline Bubbling harga rumah premium & 0,05 & 3 & 0,15 & 1 & 0,05 & 2 & 0,1 & 4 & 0,2 \\
\hline Backward integration pelanggan penting & 0,12 & 2 & 0,24 & 4 & 0,48 & 3 & 0,36 & 1 & 0,12 \\
\hline \multicolumn{10}{|l|}{ Kekuatan } \\
\hline Dukungan pusat teknikal dan inovasi global & 0,03 & 2 & 0,06 & 1 & 0,03 & 4 & 0,12 & 3 & 0,09 \\
\hline $\begin{array}{l}\text { Tingkat kepuasan pelanggan akan kualitas dan } \\
\text { konsistensi yang tinggi }\end{array}$ & 0,08 & 4 & 0,32 & 1 & 0,08 & 2 & 0,16 & 3 & 0,24 \\
\hline Fleksibilitas produksi yang cukup tinggi & 0,05 & 2 & 0,1 & 1 & 0,05 & 4 & 0,2 & 3 & 0,15 \\
\hline Dukungan keuangan yang cukup kuat & 0,02 & 2 & 0,04 & 1 & 0,02 & 4 & 0,08 & 3 & 0,06 \\
\hline Team marketing yang solid & 0,03 & - & & - & & - & & - & \\
\hline Lokasi pabrik dekat dengan customer & 0,07 & 4 & 0,28 & 1 & 0,07 & 2 & 0,14 & 3 & 0,21 \\
\hline \multicolumn{10}{|l|}{ Kelemahan } \\
\hline Komponen biaya administrasi cukup tinggi & 0,1 & 1 & 0,1 & 2 & 0,2 & 4 & 0,4 & 3 & 0,6 \\
\hline Komponen biaya bahan baku cukup tinggi & 0,15 & 1 & 0,15 & 2 & 0,3 & 4 & 0,6 & 3 & 0,45 \\
\hline Tidak memiliki sumber tambang sendiri & 0,12 & 1 & 0,12 & 2 & 0,24 & 4 & 0,48 & 3 & 0,36 \\
\hline $\begin{array}{l}\text { Tingkat kepuasan pelanggan akan harga produk } 60 \\
\text { (maks. 100) dengan grade cukup }\end{array}$ & 0,15 & 1 & 0,15 & 2 & 0,3 & 4 & 0,6 & 3 & 0,45 \\
\hline TOTAL & & & 4,01 & & 2,67 & & 4,86 & & 5,38 \\
\hline
\end{tabular}


Hasil analisis QSPM Matrix, maka urutan peringkat untuk ke-empat alternatif strategi yang tersedia adalah berikut: 1) Strategi pengembangan produk baru untuk segmen sanitaryware/ tableware dengan nilai TAS: 5,38. Strategi ini dapat dijalankan dengan cara lebih aktif memasarkan pilihan-pilihan portfolio baru dari korporat atau memanfaatkan dukungan pusat teknikal dan inovasi global untuk mengembangkan produk; 2) Strategi pengembangan pasar, penetrasi pasar dan pengembangan produk baru untuk segmen cat dan coating dengan nilai TAS: 4,86. Strategi ini dapat dijalankan dengan cara memperluas jaringan pemasaran dan memanfaatkan dukungan pusat teknikal dan inovasi global untuk mengembangkan produk baru; 3) Strategi pengetatan biaya untuk segmen keramik ubin dengan nilai TAS: 4,01. Strategi ini dapat dilakukan dengan memperbaiki inefisiensi yang terjadi di dalam PT. XYZ pada bagian operasional dan administrasi; 4) Strategi pengetatan biaya untuk segmen konstruksi dan energi dengan nilai TAS: 2,6. Strategi ini dapat dilakukan dengan memperbaiki inefisiensi yang terjadi di dalam PT. XYZ pada bagian operasional dan administrasi.

\section{Pengembangan Produk Baru}

Strategi pengembangan produk yang menjadi strategi prioritas utama PT XYZ selanjutnya dianalisis lebih dalam untuk mencari strategi fungsional yang sesuai. Langkah kunci awal menurut Cooper et al. (1997a) adalah pemilihan produk yang sesuai dengan tepat ( $d o$ the right project) dari antara semua kandidat portofolio produk yang tersedia. Metode pemilihan yang dipakai dalam penelitian ini adalah dengan memperbandingkan tingkat kepentingan kandidat portfolio produk baru dengan kandidat produk baru lainnya secara berpasangan. Dari hasil wawancara didapatkan empat kandidat portfolio NPD yaitu produk A (mineral baru), produk B (mineral berbasis silika), produk C (mineral berbasis feldspar) dan produk D (mineral baru), untuk dipilih tingkat kepentingannya berdasarkan indikator streategis berupa competitiveness, attractiveness, risks, profit, invested resources dan development period (Jang, 2016).

Hasil penilaian oleh panel ahli selanjutnya dianalisis dengan metode AHP menggunakan program Expert Choice seperti disajikan Gambar 5 dan Tabel 5. Dari hasil penilaian berpasangan antar produk yang disajikan Tabel 5, produk A dinilai memiliki profil produk yang akan menghasilkan profit menarik dengan bobot nilai 0,551 , tetapi memiliki risiko yang kurang menarik (high risk) dengan bobot nilai 0,07 dan modal investasi yang kurang menarik (high investment) dengan bobot nilai 0,056. Sebaliknya produk B dianggap akan menghasilkan profit yang tidak terlalu besar dengan nilai AHP 0,131 tetapi memiliki risiko yang menarik (low risk) dengan nilai AHP 0.450 dan modal investasi yang menarik (low investment) dengan nilai AHP 0,433 . Profil produk D dinilai hampir mirip dengan produk $\mathrm{B}$ sedangkan profil produk $\mathrm{C}$ dinilai hampir mirip dengan produk A dilihat dari sisi profit, risiko dan modal investasi pengembangan produk.

Tabel 5. Rangkuman hasil analisa perbandingan berpasangan AHP

\begin{tabular}{lccccc}
\hline Kriteria & Produk A & Produk B & Produk C & Produk D & Total \\
\hline Competitiveness & 0,077 & 0,605 & 0,085 & 0,223 & 0,057 \\
Attractiveness & 0,549 & 0,102 & 0,297 & 0,053 & 0,057 \\
Risk & 0,070 & 0,450 & 0,064 & 0,415 & 0,223 \\
Profit & 0,551 & 0,131 & 0,274 & 0,044 & 0,480 \\
Invested Resource & 0,056 & 0,433 & 0,098 & 0,413 & 0,130 \\
Development periode & 0,071 & 0,529 & 0,075 & 0,325 & 0,052 \\
\hline Total & 0,307 & 0,299 & 0,176 & 0,218 & 1,0 \\
\hline
\end{tabular}




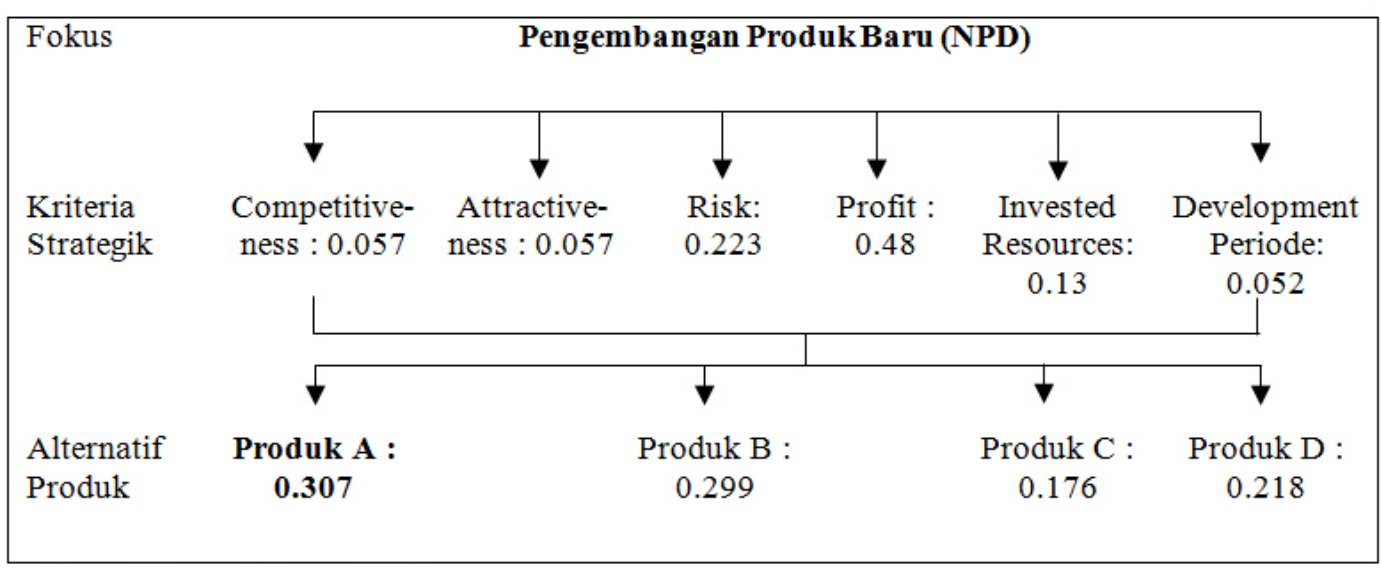

Overall inconsistency: 0.04

Gambar 5. Hasil analisis AHP Strategi NPD PT. XYZ

Hasil analisis AHP, dapat disimpulkan bahwa PT. XYZ menjadikan profit sebagai indikator strategis utama dengan nilai 0.48 diikuti dengan risk dengan nilai 0,223 , dan invested resource dengan nilai 0,13 melengkapi tiga besar indikator terpenting dalam pengembangan suatu produk baru. Hasil ini mencerminkan karakteristik team NPD PT. XYZ yang lebih mementingkan kinerja dan risiko finansial dalam mengambil sebuah keputusan mengenai NPD (Pinto dan Matel, 1990; Freeman dan Bale, 1992; Cooper dan Kleinschmidt, 2007; Pitta dan Pitta, 2012; Park et al. 2016).

Menggunakan analisa multi kriteria terhadap pilihan produk baru yang tersedia, didapatkan urutan prioritasi produk yang akan dikembangkan adalah sebagai berikut: Prioritas pertama adalah kandidat produk baru A dengan nilai 0,307 ; Prioritas kedua adalah kandidat produk baru B dengan nilai 0,299; Prioritas ketiga adalah kandidat produk baru D dengan nilai 0,218; Prioritas keempat adalah kandidat produk baru C dengan nilai 0,176 .

Pengembangan Produk A sebagai prioritas di PT. XYZ tidak serta merta meninggalkan pengembangan produk B, D dan C. Nilai prioritasi pengembangan produk baru di atas dapat dijadikan dasar pertimbangan untuk menentukan distribusi alokasi sumber daya dalam program $R \& D$ (investasi tambahan, SDM) maupun waktu pengembangan yang dibutuhkan dalam proses pengembangannya agar berjalan dengan lebih baik (Cooper dan Kleinschmidt, 2007).

\section{Implikasi Manajerial}

Hasil analisis perumusan strategi memaparkan kekuatan, kelemahan, peluang dan ancaman serta strategi yang dapat dilakukan perusahaan lima tahun mendatang dalam bersaing di bisnis mineral industrial di Indonesia. Berdasarkan hasil analisis dalam perumusan strategi bisnis dan prioritasi pengembangan produk baru yang telah dilakukan maka PT. XYZ perlu Menyusun budget penjualan tahunan dengan porsi yang lebih agresif. Budget yang disusun setidaknya mencerminkan rencana pertumbuhan bisnis yang telah ada ditambah potensi peluang pertumbuhan bisnis melalui strategi pengembangan pangsa, penetrasi pasar dan pengembangan produk. Selanjutnya, membuat proposal bisnis untuk pengembangan produk baru berdasarkan prioritasi produk yang akan dikembangkan. Di samping itu, perlu mengkaji ulang organisasi dan sumber daya pada departemen yang melaksanakan NPD dengan pertimbangan adanya penambahan beban kerja baru dan membuat rencana mitigasi risiko dari strategi pengembangan produk yang memiliki tingkat resiko yang tinggi (produk A dan produk C).

\section{KESIMPULAN DAN SARAN}

\section{Kesimpulan}

Hasil analisis berbagai faktor eksternal-internal sampai tahap perumusan strategi bisnis perusahaan maka ada empat strategi yang dapat dijalankan oleh PT. XYZ dalam bersaing di industri tepung mineral industrial 
di Indonesia dengan urutan daya tarik (attractiveness) sebagai berikut: 1) Strategi pengembangan produk baru untuk segmen sanitaryware/tableware, 2) Strategi penetrasi pasar, pengembangan pasar dan pengembangan produk untuk segmen cat dan coating, 3) Strategi pengetatan biaya untuk mendukung penetrasi pasar segmen keramik ubin dan 4) Strategi pengetatan biaya (retrenchment) untuk segmen konstruksi dan energi. Atas dasar skor terbobot setiap kriteria stratejik yang digunakan, prioritasi tertinggi NPD dalam rangka mendukung strategi pengembangan produk adalah produk A. Skor terbobot setiap portofolio NPD yang diperoleh dapat digunakan sebagai pertimbangan alokasi sumber daya untuk program R\&D.

\section{Saran}

Untuk lebih memperkaya hasil penelitian ini, disarankan untuk mendapatkan responden pihak eksternal khususnya dari pihak pemerintah sebagai pembina dan regulator dan pihak asosiasi dan tenaga ahli. Untuk mengembangkan hasil penelitian ini, peneliti menyarankan untuk membahas strategi fungsional yang sesuai bagi industri mineral industrial, yakni strategi pengembangan pasar dan strategi penetrasi pasar berdasarkan pendekatan pemasaran dan pengetatan biaya. Di samping itu, disarankan untuk menganalisa lebih dalam mengenai isu sustainability terkait dengan over exploitation tambang pasir yang sedang berlangsung mengingat industri ini sangat bergantung pada sumber daya alam yang tidak terbarukan.

\section{DAFTAR PUSTAKA}

Ansoff HI,McDonnell E. 1990. Implanting Strategic Management. 2nd edition. New Jersey: Prentice Hall.

Clark KB, Fujimoto T. 1991. Product Development Performance: Strategy, Organization, and Management in the World Auto Industry. Boston: Harvard Business School Press.

Cooper RG, Edgett SJ, Kleinschmidt EJ. 1997a. Portofolio management in new product development: lessons from the leader I. Research Technology Management 40(5): 16-28. https:// doi.org/10.1080/08956308.1997.11671152.

Cooper RG, Edgett SJ, Kleinschmidt EJ.1997b Portofolio management in new product development: lessons from the leader I. Research Technology Management 40(6): 43-52. https:// doi.org/10.1080/08956308.1997.11671170.

Cooper RG, Edgett SJ, Kleinschmidt EJ. 1998. Best practises for managing $\mathrm{r} \& \mathrm{~d}$ portfolio. Research Technology Management 41(4): 20-33. https:// doi.org/10.1080/08956308.1998.11671219.

Cooper R G. dan Kleinschmidt E J. 2007. Winning business in product development: the critical success factors. Research Technology Management 50(3): 52-66. https://doi.org/10.1 080/08956308.2007.11657441.

David FR. 2011. Strategic Management Concepts and Cases. New Jersey: Pearson Education Inc.

Freman M, Beale P. 1992. Measuring project success. Project Management Journal 23(1): 8-17.

Gorbos G. 2016. Effective product portfolio management. Journal of Business Forecasting Winter 2015-2016 : 33-35.

Jang SH. 2016. A study on r\&d performance maximization portfolio analysis technique using ahp. International Review of Management and Business Research 5(1):225-233.

Katsiouleris B. 2011. Strategic marketing of industrial minerals. The Decade ahead. Mining Engineering 63(1): 34-39.

Killen CP, Hunt RA, Kleinschmidt EJ. 2008. Project portfolio management for product innovation. International Journal of Quality and Reliability Management 25(1): 24-38. https://doi. org/10.1108/02656710810843559.

Lapide L. 2016. What about Product Portfolio Optimization. Journal of Business Forecasting. Winter 2015-2016 : 21-24.

Lismore SS. 2014 April 28. Innovation will lead the Way for Industrial Minerals. Industrial Minerals Magazine

Lofsten H. 2014. Product innovation Processes and the trade-off between product innovation performance and business performance. European Journal of Innovation Management 17(1): 61-84. https://doi.org/10.1108/EJIM-042013-0034.

McRea, Elizabeth A. 2004. Aligning product development and business strategy [disertasi]. New Jersey: The State University of New Jersey

Merriman D. 2016. Industrial Minerals Snapshot. Ceramic Industry Magazine. https://www. ceramicindustry.com/articles/95807-industrialminerals-snapshot [2019 Jan 9]

Park WK, Lee KS, Doo SY, Yoon SS. 2016. Investment for new product development: a break-even time 
analysis. Engineering Management Journal 28(3): 158-167. https://doi.org/10.1080/104292 47.2016.1199747.

Pinto J, Mantel S. The cause of project failure. IEEE Engineering Management 37(4): 269-276. https://doi.org/10.1109/17.62322.

Pitta DA, Pitta E. 2012. Transforming the nature and scope of new product development. Journal of Product and Brand Management. 21(1): 35-46. https://doi.org/10.1108/10610421211203097.
Relich M, Bzdyra K. 2014. Estimating new product success with the use of intelligent system. Foundation of Management 6(2): 7-20. https:// doi.org/10.1515/fman-2015-0007.

Slack N, Brandon-Jones A, Johnston R. 2013. Operation Management 7th edition. New Jersey: Pearson Education Limited.

Wilson TB, Amavilah VH. 2007. The economic value of industrial minerals and rocks for developing countries: a discussion of key issues. MPRA Paper 2214. 